\title{
CARACTERIZAÇÃO MINERALÓGICA PARA FINS TURÍSTICOS DAS AREIAS DE PONTA NEGRA - NATAL/RN/BRASIL
}

\author{
J. Y. P. LEITE ${ }^{1}$, F. ARAÚJO ${ }^{2}$ e B. M. S. ARAÚJO \\ Laboratório de Processamento Mineral - IFRN \\ E-mail: jyp.leite@ifrn.edu.br ${ }^{1}$; franciolliaraujo@gmail.com²
}

Artigo submetido em novembro/2013 e aceito em julho/2014

DOI: http://dx.doi.org/10.15628/holos.2014.1834

\section{RESUMO}

A praia de Ponta Negra esta localizada em Natal, capital do Rio Grande do Norte, sendo esta o principal cartão postal do Estado que é caracterizado por uma grande duna margeada pela Mata Atlântica. Com o objetivo de gerar produtos voltados para desenvolvimento do turismo, associando temas da área mineral foi coletada amostra próximo ao Morro do Careca, seguida de classificação granulométrica, separação em meio denso e identificação mineralógica com técnicas de microscopia ótica e em MEV. Em seguida, as imagens foram tratadas e gerados produtos associando os minerais identificados (quarzto, epidoto, rutilo, magnetita, titanita, ilmenita, zirconita) na areia de praia com a paisagem da região. As imagens deverão ser utilizadas na geração de produtos, tais como cartões postais, pôsteres, camisetas, bateias, folders, livros, entre outros. Este trabalho elevará a divulgação e valoração da área mineral, bem como fomentará empreendimentos voltados para a divulgação científica

PALAVRAS-CHAVE: mineralogia, areia de praia, caracterização, turismo, divulgação científica

\section{PONTA NEGRA'S SAND BEACH MINERALOGICAL CHARACTERIZATION FOR TURISTIC ENDS - NATAL/RN/BRAZIL}

\section{ABSTRACT}

The Ponta Negra beach is located in Natal, the capital of Rio Grande do Norte State.It is the main postcard of the state and is characterized by a large dune bordered by the Atlantic Forest. Aiming to generate products for tourism development, combining themes of the mineral sciences, samples were collected near the Morro do Careca, followed by particle size classification, dense medium separation and mineralogical identification with optical microscopy and SEM. Then the images were
\end{abstract}

generated by associating the identified mineral components (quarzto, epidote, rutile, magnetite, titanite, ilmenite, zirconite) of the beach sand with the landscape. Images can be used in products such as postcards, posters, t-shirts, folders, books and others. This work will increase dissemination and valuation of mineral sciences and encourage enterprises aimed at these goals.

KEYWORDS: mineralogy; beach sand; characterization; tourism; scientific dissemination. 


\section{INTRODUÇÃO}

O Governo brasileiro observa que é necessário ampliar as ações de difusão científica, tendo em vista alertar a sociedade para a importância do investimento em ciência e tecnologia. Essa importância é refletida pelo lançamento de editais de fomento para a popularização da ciência, bem como a valorização de espaços no currículo Lattes do CNPq para esta área (CNPq, 2012). É observada uma grande mobilização nacional para a criação de olimpíadas com este objetivo, tais como as de Matemática, Física, Química, Biologia, entre outras.

A área mineral responde por 4,2 \% do PIB (Plano Nacional de Mineração 2030, 2011) e não é observada uma política de difusão científica para a área com o objetivo de estimular a juventude.

Dantas et al (1997) utilizaram técnicas de análise granulométrica, separação em meio denso e microscopia por lupa binocular para caracterizar as areias da praia de Ponta Negra, concluindo que $89 \%$ do material encontra-se na faixa $-420 \#+210 \#$, sendo classificadas do ponto da sedimentologia como areias, onde predominam os minerais epídoto, ilmenita, magnetita, quartzo, rutilo, titanita e zirconita, com a proporção de quartzo reduzindo-se com a redução da granulometria, característica de sua alta resistência ao intemperismo. Dentre os minerais pesados, predomina a ilmenita.

Este trabalho propõe apresentar as características dos minerais presentes em amostra coletada na praia de Ponta Negra, em Natal-RN, criando alternativas de valoração e difusão científica à área de tecnologia mineral.

Trabalhos de caracterização granulométrica, mineralógica e microscópica (óptica e eletrônica de varredura) se propõem desenvolver alternativas não convencionais para divulgação da tecnologia mineral, associando os recursos minerais a produtos turísticos, utilizando-se, para isto, as imagens dos minerais microscópicos encontrados nos areias da Praia de Ponta Negra e a paisagem de recursos naturais como o Morro do Careca (um dos principais cartões postais da cidade).

Esforços para a valoração da geodiversidade brasileira podem ser observados em trabalho realizados por Machado \& Ruchkys (2010) do IGC da UFMG e programas com estes objetivos precisam ser intensificados no país.

A demanda por profissionais para a área de engenharia mineral se mostra crescente, mas a quantidade de profissionais no mercado ainda é insuficiente para atendar a demanda (Koppe, 2010). Dessa forma, é necessário realizar esforços para despertar o interesse da juventude nesta área de conhecimento, o que pode ser feito através da associação da caracterização de bens minerais com o uso intensivo de novos equipamentos.

\section{PROCEDIMENTOS EXPERIMENTAIS E RESULTADOS}

A amostra foi coletada a partir de uma malha retangular de $1.000 \mathrm{~m} 2$ (espaçamento de 10 $m$ entre os poços e profundidade de até $20 \mathrm{~cm}$ ). 
A amostra gerada pesou aproximadamente $240 \mathrm{~kg}$, a qual foi seca em estufa a 110 ㄷ $\mathrm{C}$ por $24 \mathrm{~h}$, sendo então homogeneizada e quarteada pelos métodos de pilha longitudinal e pilha cônica, obtendo-se alíquotas de 2 kg para ensaio de separação por meio de bateia.

O material retido foi seco em estufa a 110 ㅇ por $24 \mathrm{~h}$, homogeneizado e quarteado, sendo geradas alíquotas com aproximadamente $1 \mathrm{~g}$ para análise por microscopia eletrônica de varredura (MEV) e EDS para verificação da composição química dos grãos analisados.

A Figura 1 apresenta o fluxograma utilizado para realização dos ensaios.

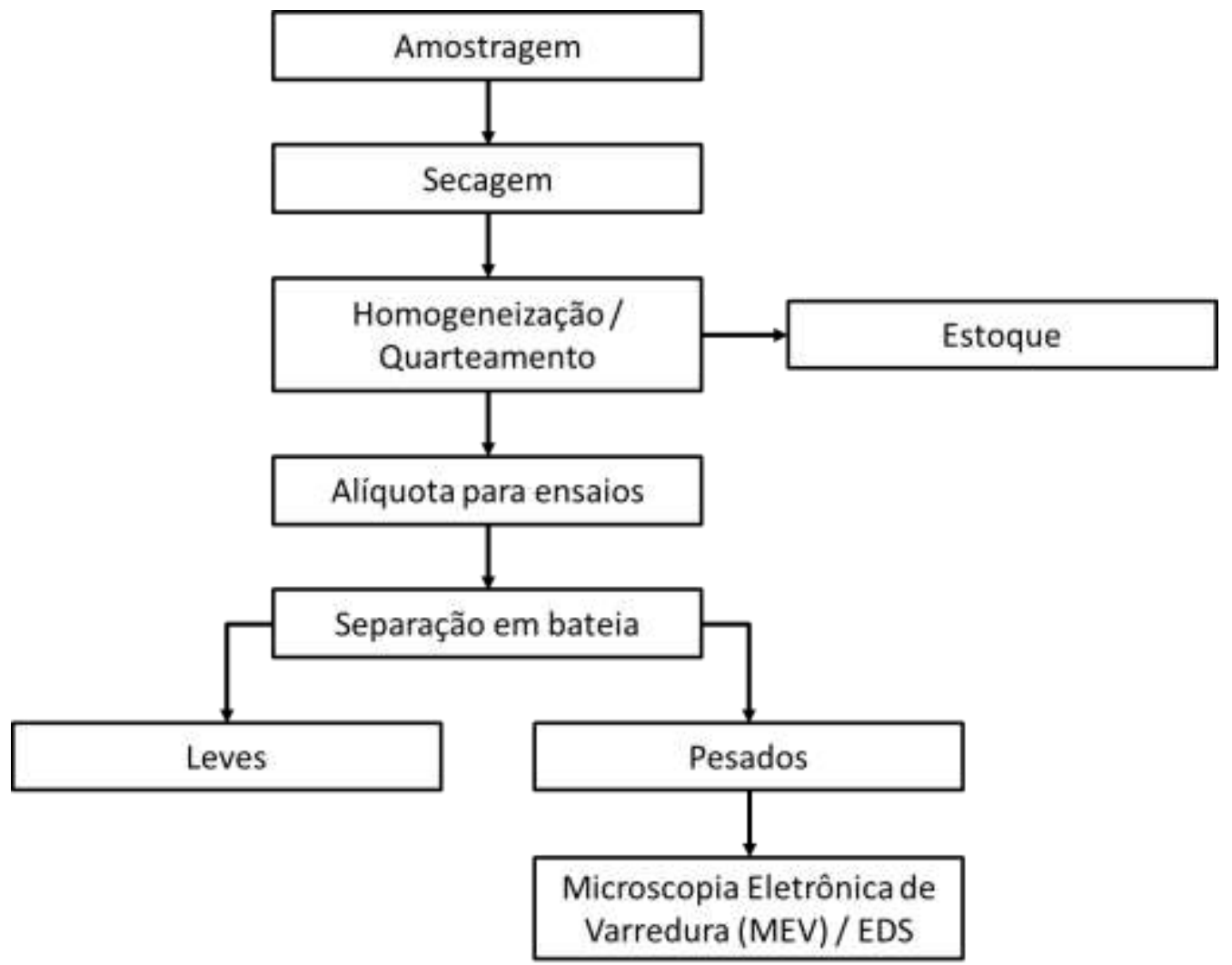

Figura 1 - Fluxograma de preparação da amostra de areia de praia de Ponta Negra.

As imagens geradas pela microscopia eletrônica de varredura mostram partículas de quartzo (Figura 2), predominante em faixas granulométricas maiores, como cristais de forma não definida. 


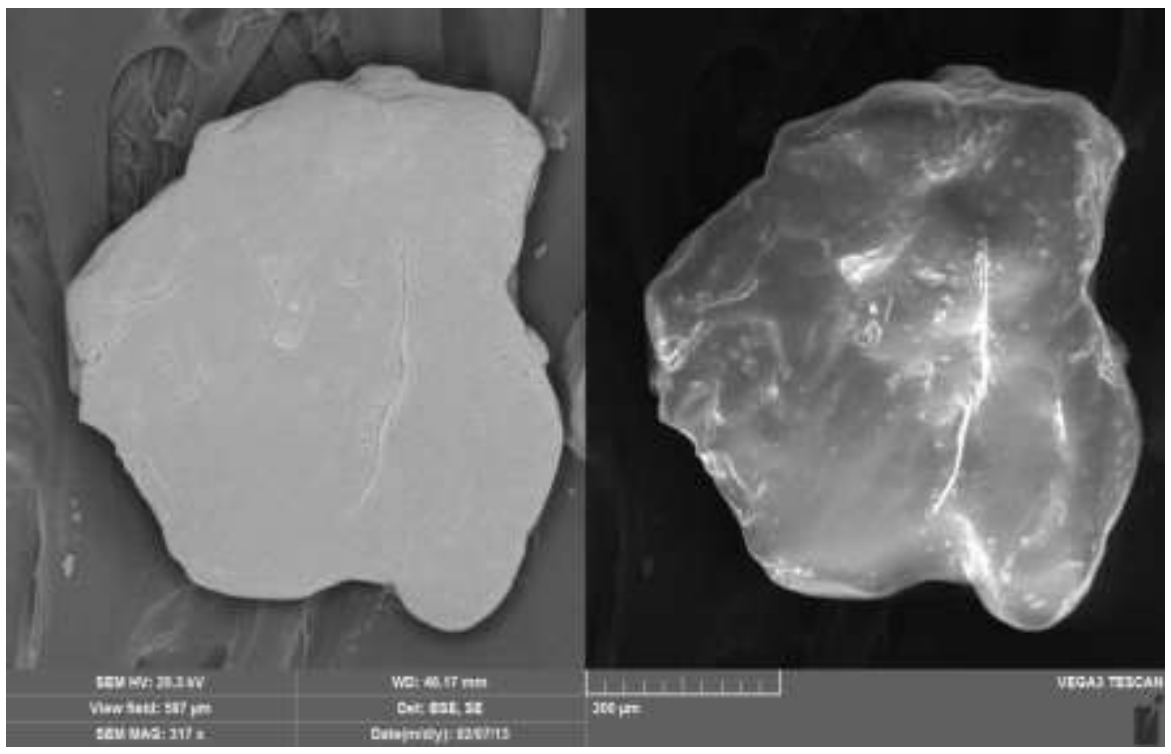

Figura 2 - Cristal de quartzo com magnificação de 317x. À esquerda, imagem gerada por elétrons retroespalhados e a direita imagem gerada por elétrons secundários.

Os grãos de elementos pesados (densos) apresentam formatos mais regulares e definidos, apesar de sua granulação mais fina. A figura 3 apresenta um grão de formato prismático, cuja composição é apresentada na Tabela I.

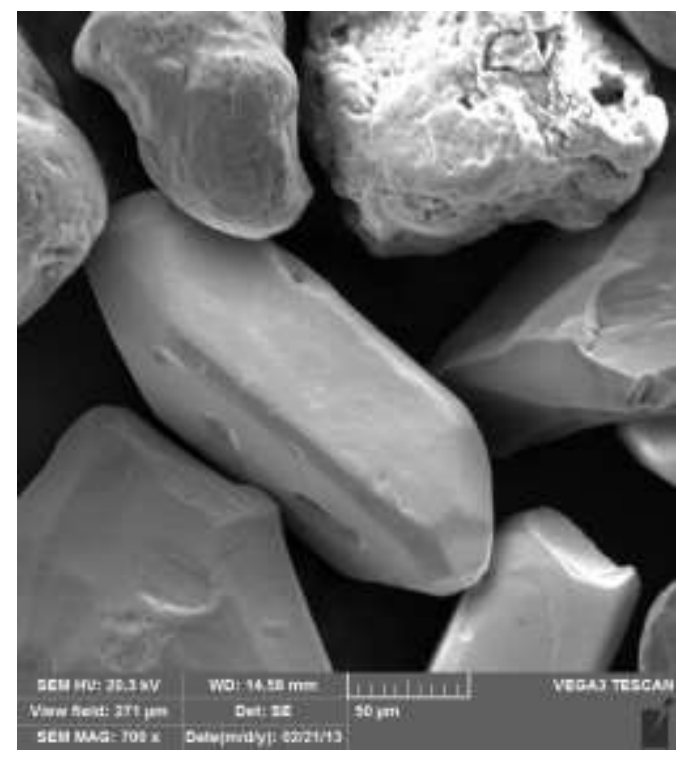

Figura 3 - Grão em formato zirconita no centro da imagem com tamanho aproximado de $145 \mu \mathrm{m}$. 
Tabela I. EDS do grão prismático apresentado na Figura 3.

\begin{tabular}{cc}
\hline ELEMENTO & $\%$ \\
\hline $\mathbf{O}$ & 36,77 \\
$\mathbf{A l}$ & 0,39 \\
$\mathbf{S i}$ & 13,59 \\
$\mathbf{T i}$ & 5,23 \\
$\mathbf{F e}$ & 0,57 \\
$\mathbf{Z r}$ & 49,64 \\
\hline
\end{tabular}

Somente a composição química não é suficiente para determinar o mineral, mas a presença de elementos pesados em sua composição, com alto teor de zircônio, pode ser um indicativo de que o mineral seja zirconita, elemento comum nas areias de praia.

Outros grãos apresentam-se na forma de triângulos, como o grão de ilmenita exibido na Figura 4, cujo EDS é apresentado na Tabela II.

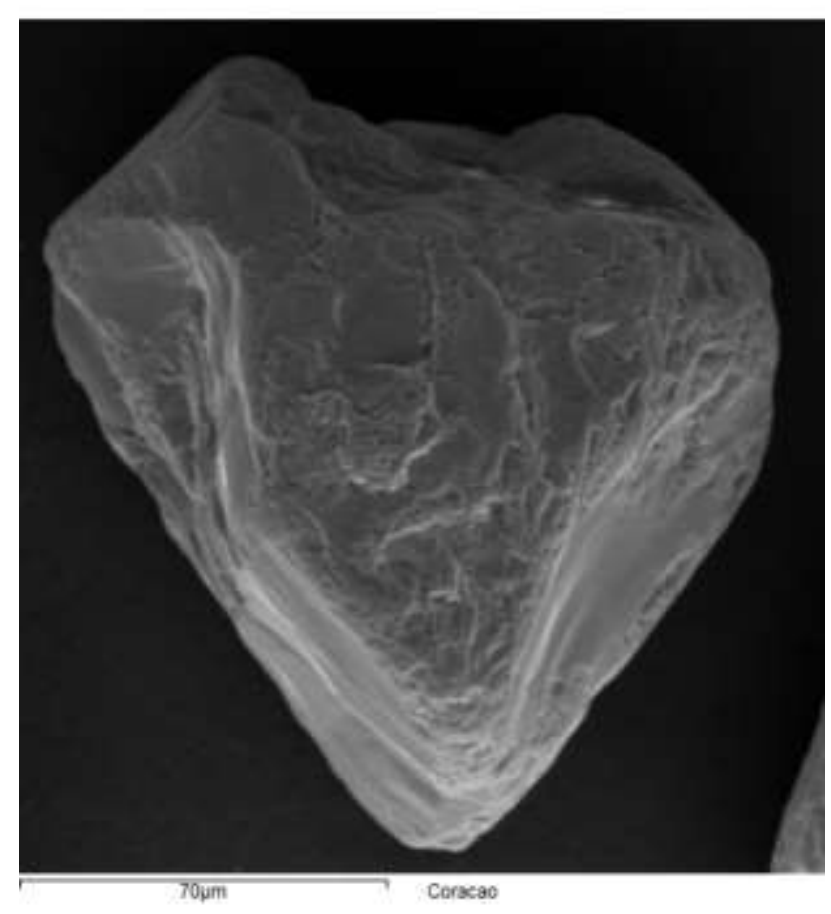

Figura 4 - Grão de ilmenita com tamanho aproximado de $140 \mu \mathrm{m}$. 
Tabela II. EDS do grão triangular apresentado na Figura 4.

\begin{tabular}{cc}
\hline Óxido & $\%$ \\
\hline $\mathrm{MgO}$ & 0,09 \\
$\mathrm{Al}_{2} \mathrm{O}_{3}$ & 0,38 \\
$\mathrm{SiO}_{2}$ & 0,49 \\
$\mathrm{TiO}_{2}$ & 57,02 \\
$\mathrm{MnO}$ & 2,16 \\
$\mathrm{FeO}$ & 39,86 \\
\hline
\end{tabular}

A difusão científica e tecnológica para a área mineral será realizada através da associação das imagens captadas no MEV dos minerais e suas variações em formas geométricas e químicas, associando-as com as belas paisagens dos recursos naturais do litoral potiguar, como mostrado nas Figuras 5 e 6.

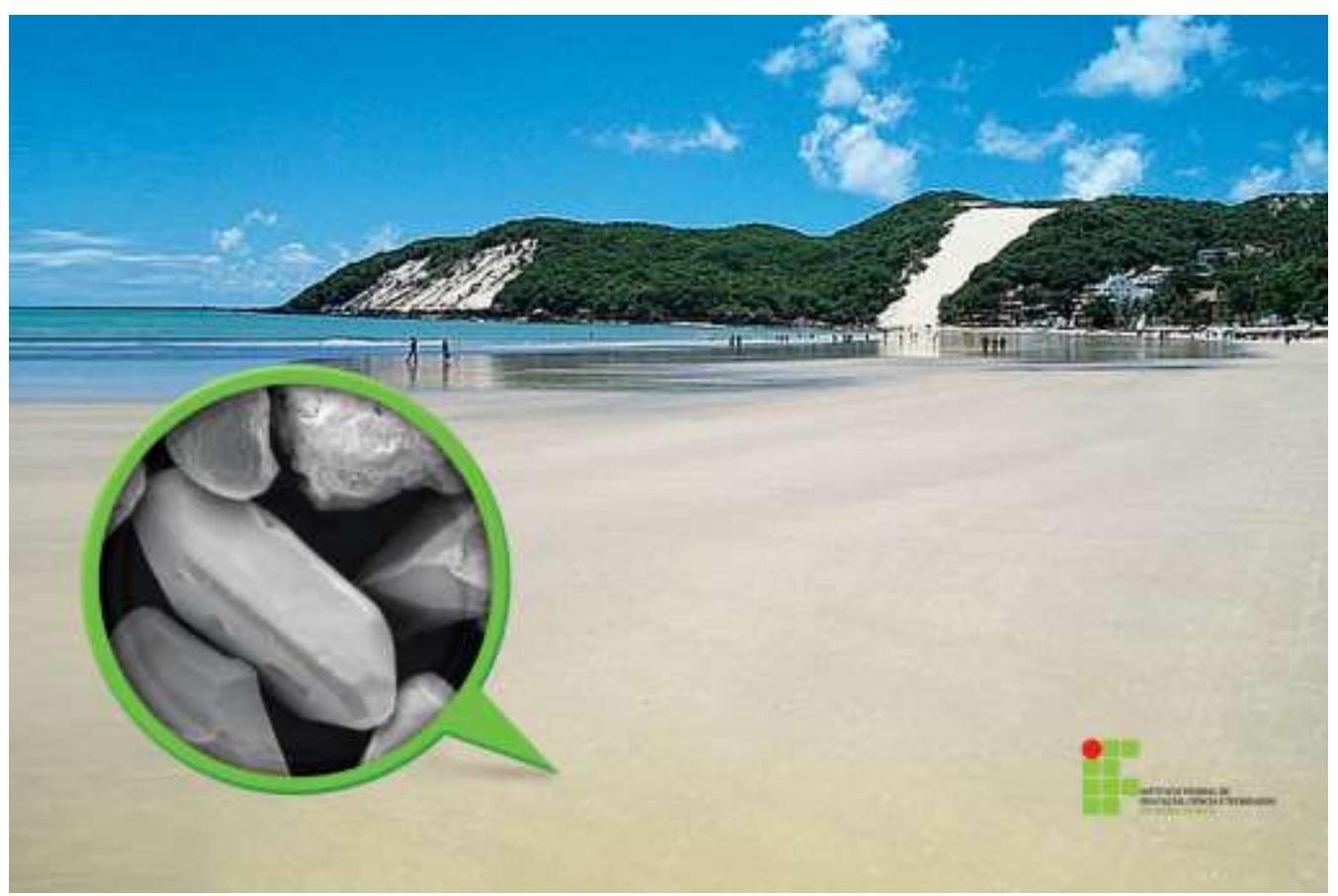

Figura 5 - Cartão postal de Ponta Negra - Natal/RN, com grãos de zirconita em destaque 


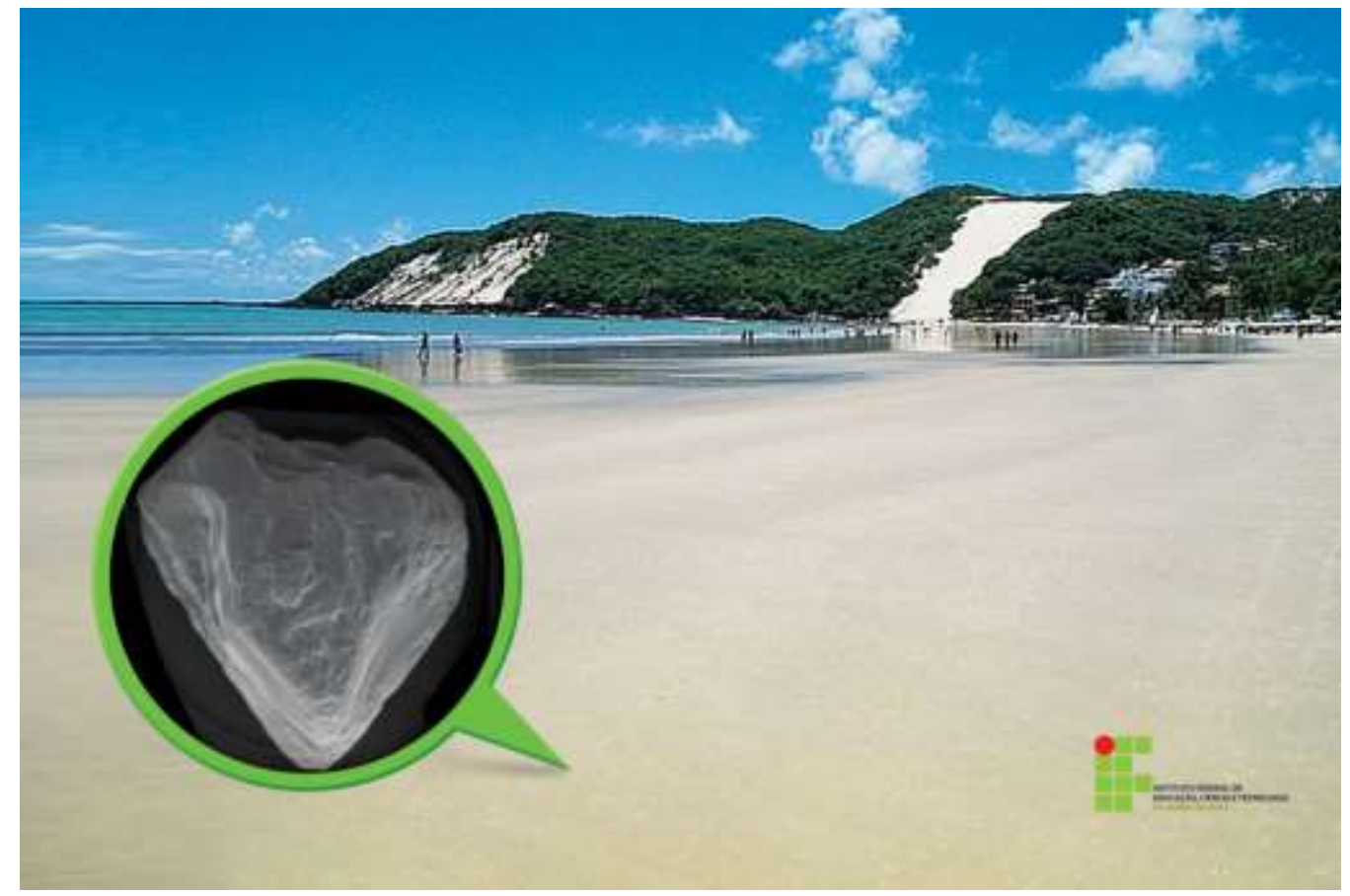

Figura 6 - Cartão postal de Ponta Negra - Natal/RN, com grão de ilmenita em destaque.

A associação de caracterização tecnológica com os eventos turísticos possibilita valorar a área de mineração no cenário brasileiro, bem como estimulará a juventude a despertar o interesse científico pela área mineral e suas técnicas de caracterização.

Essa iniciativa deve estar associada à criação de espaços permanentes de divulgação científica, como a disposição de painéis ao longo da orla, apresentando a composição mineralógica, suas técnicas e importância econômica, transformando estes espaços em um ambiente de divulgação científica voltada ao fortalecimento da área mineral brasileira.

\section{CONCLUSÃO}

As características geométricas dos minerais pesados identificados, associados às belas paisagens dos recursos naturais do litoral do Rio Grande do Norte, nos levam a propor uma aplicação não convencional à área de tecnologia mineral, ou melhor, associar os minerais presentes em cada localidade turística com uma paisagem representativa daquele lugar. Assim, poderá se desenvolver cartões postais, vídeos educativos e Turísticos, folders e outros produtos vinculados ao Turismo e a Educação.

As aplicações propostas possibilitam uma grande divulgação da área de tecnologia mineral, amplia o interesse da sociedade e, ao mesmo tempo, ampliará os interesses da juventude para a área mineral.

Outro fator relevante, neste trabalho, é que esta aplicação vem associada com um produto visual contemplativo para o lazer e elevado impacto para formalização de perguntas para a área de tecnologia mineral. O que vem a melhorar a visão da sociedade sobre a área de Mineração, que está habituada à imagem que a mídia criou, de um setor econômico que 
contribui apenas para a degradação ambiental, sem levar em consideração sua grande contribuição para o desenvolvimento econômico da sociedade moderna e do país.

\section{REFERÊNCIAS}

1. CNPq. Popularização da Ciência. 2012. Disponível em: http://goo.gl/7FSbE

2. DANTAS, J. H. A., BAYER, M. M., LIMA, L. A. S., LEITE, J. Y. P. Areia de Ponta Negra - uma aplicação não convencional. In: XVII Simpósio de Geologia do Nordeste, v. único, p. 499-501, Fortaleza, Brasil, 1997.

3. MACHADO, M. M. M., RUCHKYS, U. Z. Valorizar e Divulgar a Geodiversidade: Estratégias do Centro de Referência em Patrimônio Geológico CRPG - MHNJB/UFMG. GEONOMOS 18 (2): 53-56. 2010.

4. KOPPE, J. C. A Lavra e a Indústria Mineral no Brasil - Estado da Arte e Tendência Tecnológicas. In: Tendências Tecnológicas Brasil 2015 - Geociências e Tecnologia Mineral.2007. pp 97-99.

5. Plano Nacional de Mineração 2030. Ministério de Minas e Energia. 2011. Disponível em: http://goo.gl/Ry1Sy 